\title{
Direct Conversion of Pretreated Straw Cellulose into Citric Acid by Co-cultures of Yarrowia lipolytica SWJ-1b and Immobilized Trichoderma reesei Mycelium
}

\author{
Xiaoyan Liu • Jinshun Lv • Tong Zhang • Yuanfang Deng
}

Received: 19 November 2013 / Accepted: 10 March 2014 /

Published online: 23 March 2014

(C) Springer Science+Business Media New York 2014

\begin{abstract}
The immobilized cellulase-producing mycelium of Trichoderma reesei was found to produce $2.9 \mathrm{U} / \mathrm{ml}$ of cellulase activity within $144 \mathrm{~h}$ while $2.1 \mathrm{U} / \mathrm{ml}$ of cellulase activity was produced within $120 \mathrm{~h}$ by the free mycelium of the same strain. When the immobilized mycelium of T. reesei was co-cultivated with the free cells of Yarrowia lipolytica SWJ-1b in flask, Y. lipolytica SWJ-1b could yield $10.7 \mathrm{~g} / 1$ of citric acid and $3.9 \mathrm{~g} / \mathrm{l}$ of isocitric acid from $40.0 \mathrm{~g} / \mathrm{l}$ pretreated straw within $240 \mathrm{~h}$. Under the similar conditions, Y. lipolytica SWJ-1b could yield $32.8 \mathrm{~g} / \mathrm{l}$ of citric acid and $4.7 \mathrm{~g} / 1$ of isocitric acid from $40.0 \mathrm{~g} / 1$ pretreated straw supplemented with $20.0 \mathrm{~g} / \mathrm{l}$ glucose within $288 \mathrm{~h}$. When the co-cultures were grown in 10-1 fermentor, Y. lipolytica SWJ-1b could yield $83.4 \mathrm{~g} / 1$ of citric acid and $8.7 \mathrm{~g} / 1$ of isocitric acid from $100.0 \mathrm{~g} / \mathrm{l}$ of pretreated straw supplemented with $50.0 \mathrm{~g} / 1$ glucose within $312 \mathrm{~h}$.
\end{abstract}

Keywords Citric acid Parrowia lipolytica $\cdot$ Pretreated straw $\cdot$ Immobilization $\cdot$ SSF

\section{Introduction}

As the most versatile industrial organic acid, citric acid (CA) is extensively used in the food industry as an acidulant, preservative, buffer, emulsifier, stabilizer, and antioxidant [1]; it is also used in cosmetics and pharmaceutical industry and so on [2]. It is reported that the annual CA production in the world is 800,000 tons and increases annually by $5.0 \%$ [3].

The Aspergillus niger is the primary organism used for microbiological production of CA, while it is regarded that the yeast Yarrowia lipolytica has more advantages in CA manufacture such as having broad choice of carbon source, more tolerance to higher concentrations of substrate, greater productivity [4], and easier genetic modification by molecular techniques [5]. Sugars, plant oils, starch hydrolysates, and glycerol are the best substrates in CA production [2]; nowadays, the deficiency and the high price of the food make it urgent to use lower cost substitute of food to reduce the production cost. Many reports have pointed that a variety of

X. Liu $(\bowtie) \cdot$ J. Lv $\cdot$ T. Zhang $\cdot$ Y. Deng

Jiangsu Key Laboratory for Biomass-based Energy and Enzyme Technology, Huaiyin Normal University, Huai'an, China

e-mail: catty5082003@163.com 
carbon sources such as fruit heels and waste, factory wastes [2], and inulin [6, 7] are able to produce CA when grown under nutrient-limited conditions.

Straw is a cheap and renewable cellulosic carbon which is available all over the world. However, the complex composition (cellulose and hemicellulose intervened with lignin) of the straw makes it hard to be hydrolyzed enzymatically, while most of the lignin and hemicellulose in the straw are removed and the crystallinity of the straw cellulose is reduced in the pretreated straw, which can be hydrolyzed into glucose by cellulase [8]. This makes it possible for the pretreated straw to be a carbon resource for producing CA by Y. lipolytica.

Trichoderma reesei which could produce high activity of cellulase has been most extensively studied for cellulase production $[9,10]$ and was used to produce cellulase in this study. It is said that the cellobiose and glucose in the hydrolysate may inhibit cellulase activity, while simultaneous saccharification and fermentation (SSF) is a good way to reduce the inhibition.

Immobilized microorganism could produce enzymes that have remarkable characteristics such as higher productivity, better heat stability, and prolonged enzyme production [11]. In this study, cellulase was produced by the immobilized $T$. reesei in SSF. Sodium alginate is a promising support material for mycelium immobilization which is cheap and mechanically stable [12]; it was used to immobilize the cellulase-producing mycelium of T. reesei.

Y. lipolytica $\mathrm{SWJ}-1 \mathrm{~b}$ which has been screened for producing high yield of $\mathrm{CA}$ in our previous study [6] was used as CA producer in this study.

\section{Materials and Methods}

\section{Strains}

The cellulase producer used in this study was T. reesei. The CA producer used in this study was Y. lipolytica SWJ-1b.

\section{Media}

The spores of $T$. reesei were kept at $-80{ }^{\circ} \mathrm{C}$ in $20.0 \mathrm{~g} / \mathrm{l}$ glycerite and sprouted on PDA agar slant (200.0 g/l potato, $20.0 \mathrm{~g} / 1$ glucose, and $20.0 \mathrm{~g} / \mathrm{l}$ agar). The CA-producing strains were kept at $4{ }^{\circ} \mathrm{C}$ on YPD agar slant $(10.0 \mathrm{~g} / 1$ yeast extract, $20.0 \mathrm{~g} / 1$ peptone, $20.0 \mathrm{~g} / 1$ glucose, and $20.0 \mathrm{~g} / \mathrm{l}$ agar) and sub-cultured twice a month. Inoculum was prepared by a culture on YPD medium (10.0 g/l yeast extract, $20.0 \mathrm{~g} / 1$ peptone, and $20.0 \mathrm{~g} / 1$ glucose $)$ for $24 \mathrm{~h}$ at $28{ }^{\circ} \mathrm{C}$, $180 \mathrm{rpm}$. The medium for the produced cellulase was corn steep liquor $1.6 \mathrm{~g} / \mathrm{l}, \mathrm{CoCl}_{2} \cdot 6 \mathrm{H}_{2} \mathrm{O}$ $0.2 \mathrm{~g} / 1,\left(\mathrm{NH}_{4}\right)_{2} \mathrm{SO}_{4} 1.4 \mathrm{~g} / 1, \mathrm{KH}_{2} \mathrm{PO}_{4} 2.0 \mathrm{~g} / 1, \mathrm{MgSO}_{4} 0.3 \mathrm{~g} / 1$, pretreated straw $40.0 \mathrm{~g} / 1$, and urea $0.3 \mathrm{~g} / 1$, and the medium for the produced CA was $40.0 \mathrm{~g} / 1$ or $100.0 \mathrm{~g} / 1$ pretreated straw, $0.25 \mathrm{~g} / 1$ $\left(\mathrm{NH}_{4}\right)_{2} \mathrm{SO}_{4}, 1.7 \mathrm{~g} / 1 \mathrm{KH}_{2} \mathrm{PO}_{4}, 12.0 \mathrm{~g} / 1 \mathrm{Na}_{2} \mathrm{HPO}_{4}, 1.25 \mathrm{~g} / 1 \mathrm{MgSO}_{4} \cdot 7 \mathrm{H}_{2} \mathrm{O}, 0.25 \mathrm{~g} / 1$ yeast extract, $0.006 \mathrm{~g} / 1$ vitamin $\mathrm{B}_{1}, \mathrm{pH}$ 6.0. The latter was called as pretreated straw medium (PSM) in this paper; 20.0 or $50.0 \mathrm{~g} / \mathrm{L}$ glucose was added into PSM that contained 40.0 and $100.0 \mathrm{~g} / \mathrm{l}$ pretreated straw respectively, and they were called pretreated straw-glucose medium (PSGM) in this paper. The pretreated straw was smashed before use.

\section{Immobilization of Mycelium of T. reesei and Cellulase Production}

T. reesei was inoculated on PDA agar slant at $30^{\circ} \mathrm{C}$ for 1 week. The spores were collected and washed using sterile distilled water by centrifugation at $4,000 \mathrm{~g}$ and $4{ }^{\circ} \mathrm{C}$. The washed spores were resuspended in sterile distilled water. In $100.0 \mathrm{ml}$ of water, $5.0 \mathrm{~g}$ of sodium alginate was 
dissolved and autoclaved at $120^{\circ} \mathrm{C}$ for $20 \mathrm{~min}$. After cooling, moderate spore suspension was added to the sodium alginate solution, and the spore density in the solution was adjusted to $1.0 \times 10^{8}$ spores $/ \mathrm{ml}$. Of the solution obtained above, $5.0 \mathrm{ml}$ was dropped into the sterile solution containing $20.0 \mathrm{~g} / \mathrm{l}$ calcium chloride using a 10.0-ml disposable plastic syringe. The sodium alginate spore beads (100 beads more or less; diameter, $2 \sim 3 \mathrm{~mm}$ ) formed were immersed for $16 \mathrm{~h}$ at $4{ }^{\circ} \mathrm{C}$. The sodium alginate spore beads were washed using sterile distilled water for several times. All the beads were grown in $50.0 \mathrm{ml}$ of the cellulase production medium by shaking at $30{ }^{\circ} \mathrm{C}$ and $200 \mathrm{rpm}$. At the same time, the same amount of the spores was inoculated into $50.0 \mathrm{ml}$ of the cellulose production medium and cultured under the same conditions. The cellulase activity released from the immobilized and the free mycelia of $T$. reesei was then determined.

\section{Determination of Cellulase Activity}

The cultures for producing cellulase were centrifuged at $4,000 \mathrm{~g}$ and $4{ }^{\circ} \mathrm{C}$. The filter paper activity (FPA) of the cellulase was quantitatively determined by Tangnu et al. [13]. One cellulase unit (U) was defined as the amount of enzyme that produces $1 \mu \mathrm{mol}$ of reducing sugar per minute under the assay conditions used in this study.

\section{CA Production in PSM and PSGM}

The immobilized spores of $T$. reesei were grown respectively in $50.0 \mathrm{ml}$ PSM and PSGM containing $40.0 \mathrm{~g} / \mathrm{l}$ pretreated straw cellulose and then shaking at $30^{\circ} \mathrm{C}$ and $200 \mathrm{rpm}$ for $24 \mathrm{~h}$. Of Y. lipolytica SWJ-1b cell culture which had been grown in liquid YPD medium for $24 \mathrm{~h}$, $1.0 \mathrm{ml}\left(\mathrm{OD}_{600}=30\right)$ was transferred into PSM and PSGM containing the immobilized T. reesei, then the co-cultures were continued to be grown as the method of producing CA. The methods of producing CA and determination were described by Liu et al. [6].

\section{CA Production from the Pretreated Straw During 10-1 Fermentation}

The fermentation was carried out in a 10-1 fermentor. The immobilized spores (around 1,600 sodium alginate spore beads obtained above) of T. reesei were grown in 8.01 of the PSGM in the 10-1 fermenter. The fermentation was performed under the conditions of the aeration rate of $10 \mathrm{l} / \mathrm{min}$, the temperature of $30{ }^{\circ} \mathrm{C}$, without agitation (avoiding disruption of the sodium alginate spore beads), and the fermentation period of $24 \mathrm{~h}$, then $160.0 \mathrm{ml}\left(\mathrm{OD}_{600}=30\right)$ of Y. lipolytica SWJ-1b cell culture which had been grown in YPD medium for $24 \mathrm{~h}$ was transferred into the culture containing the immobilized spores of $T$. reesei cell co-cultures that were continued to be grown under the same conditions, except the temperature being adjusted to $28{ }^{\circ} \mathrm{C}$. The cellulase activity and the concentration of the total sugar, reducing sugar, $\mathrm{CA}$, and isocitric acid (ICA) were determinated during the fermentation.

Determination of Total Sugar, Reducing Sugar, Cellulase Activity, CA, and ICA in the Fermented Media

Reducing sugar in the fermented media was determined by the Nelson-Somogyi method [14]. Total sugar was measured as the methods described by Chi et al. [15]. Cellulase FPA was determined by the methods described as "Determination of Cellulase Activity". CA was estimated by the methods described by Camp and Farmer [16]. ICA in the supernatant was determined using D-isocitric acid (D-isocitronensaure) kit produced by Germany Boehringer Mannheim. 


\section{Results and Discussion}

\section{Immobilization of Spores of T. reesei and Cellulase Production}

In order to directly convert the pretreated straw cellulose into CA by Y. lipolytica SWJ-1b and avoid mixing the cells of Y. lipolytica SWJ-1b with the mycelia of T. reesei, it is important to cultivate the immobilized $T$. reesei and the free cells of $Y$. lipolytica $\mathrm{SWJ}-1 \mathrm{~b}$ in the same culture; moreover, the co-culture can avoid the inhibition of high hydrolysate concentration to cellulase activity at the same time. In this case, the immobilized mycelia of $T$. reesei synthesize cellulase and secrete it into the medium so that the cellulose can be hydrolyzed, then the hydrolysate was utilized and converted to CA simultaneously by the free cells of Y. lipolytica SWJ-1b.

In recent years, sodium alginate has been extensively used for microbial immobilization $[17,18]$, and it was used to immobilize the mycelia of $T$. reesei in this study. The results show that the most suitable condition for immobilization of the spores and the cellulase production is $5.0 \mathrm{ml}$ of the spore suspension $\left(5.0 \times 10^{8}\right.$ spores $\left./ \mathrm{ml}\right)$ mixed with $20.0 \mathrm{ml} 50.0 \mathrm{~g} / \mathrm{l} \mathrm{sterile} \mathrm{sodium}$ alginate and then dropped into $50.0 \mathrm{ml} 20.0 \mathrm{~g} / \mathrm{l}$ sterile anhydrous calcium chloride. Under such conditions, all the mycelia of $T$. reesei were kept within the beads, and all the beads were maintained perfect during the whole cultivation period (Fig. 1). The immobilized mycelia of T. reesei and the free cells of Y. lipolytica SWJ-1b were aerobically grown in the PSM containing $40.0 \mathrm{~g} / \mathrm{l}$ pretreated straw, and the time course of cellulase production was determined. The results in Fig. 2 indicate that the immobilized cells could produce $2.9 \mathrm{U} / \mathrm{ml}$ of cellulase activity (FPA) within $144 \mathrm{~h}$ while the free cells of the same yeast strain only produced $2.1 \mathrm{U} / \mathrm{ml}$ of cellulase activity within $120 \mathrm{~h}$. In Moosavi-Nasab and Majdi-Nasab's study, sugar beet pulp was used by $T$. reesei to produce cellulase, and the maximum of FPA reached to $0.5 \mathrm{U} / \mathrm{ml}$ within 5 days [19]. With steam-treated willow, T. reesei RUT C30 could produce cellulase with the FPA of $1.6 \mathrm{U} / \mathrm{ml}$ [20], while $3.3 \mathrm{U} / \mathrm{ml}$ of cellulase (FPA) was produced by Trichoderma viride QM 6a with lka floc [21]. Thus, the FPA of cellulase produced by T. reesei with the pretreated straw is higher than most of the cellulase produced by other strains with the materials mentioned above. Since the pretreated straw is abundant in the locality, it will be used in cellulase production and further used in CA production in this study.
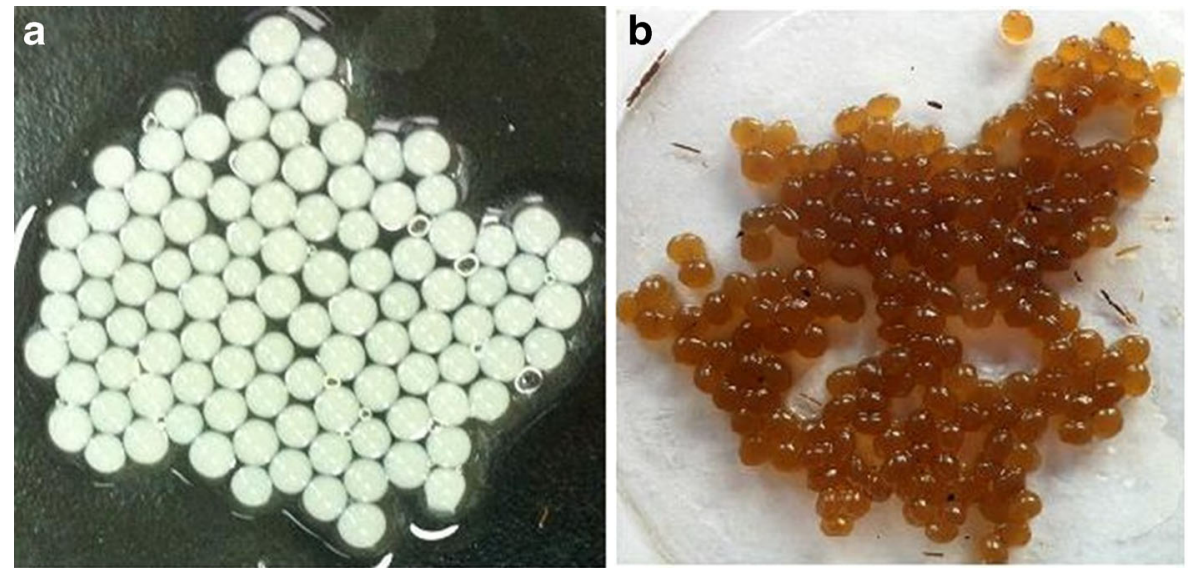

Fig. 1 The photos of beads before (a) and after (b) cultivation 


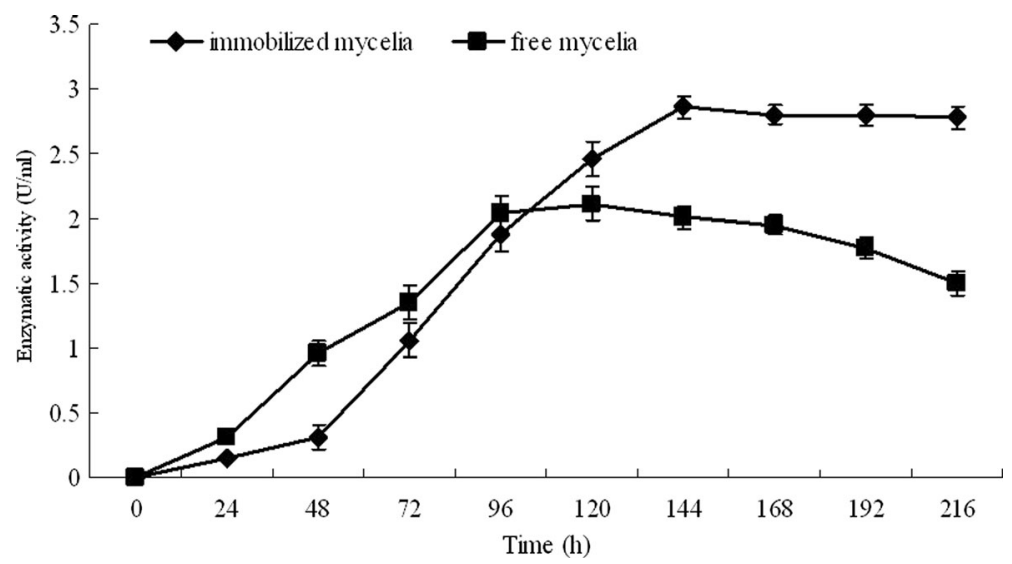

Fig. 2 Cellulase activity of immobilized and free mycelia of $T$. reesei. Data are given as means $\pm \mathrm{SD}, n=3$

Zhao et al. [22] found that immobilized cells and free cells of Pichia guilliermondii M-30 could produce 167.4 and $124.3 \mathrm{U} / \mathrm{ml}$ of inulinase activity respectively. The results imply that the immobilized cells could produce enzymes with higher activities than the free cells of the same strains. Moreover, immobilized microorganism showed many advantages compared to that of the free ones, such as being more tolerant to the external environment and supporting a long-lasting production of enzymes [23, 24].

\section{Direct Conversion of the Pretreated Straw into CA at the Flask Level}

After the immobilized mycelia of $T$. reesei were co-cultivated with the free cells of $Y$. lipolytica SWJ-1b in the PSM containing $40.0 \mathrm{~g} / 1$ pretreated straw, the concentration of CA and ICA in the fermentation broth was determined as described in "Materials and Methods". The result in Fig. 3 shows that the CA and ICA yields of Y. lipolytica SWJ-1b were $10.7 \mathrm{~g} / 1$ (reached to the maximum at $192 \mathrm{~h}$ ) and $3.9 \mathrm{~g} / \mathrm{l}$, respectively, and the cellulase activity reached to $2.3 \mathrm{U} / \mathrm{ml}$ at $168 \mathrm{~h}$ and persisted until the end of the cultivation $(240 \mathrm{~h})$. The results in Fig. 3 also indicate that $82.5 \%$ of pretreated straw in the medium was utilized by the co-cultures. When only

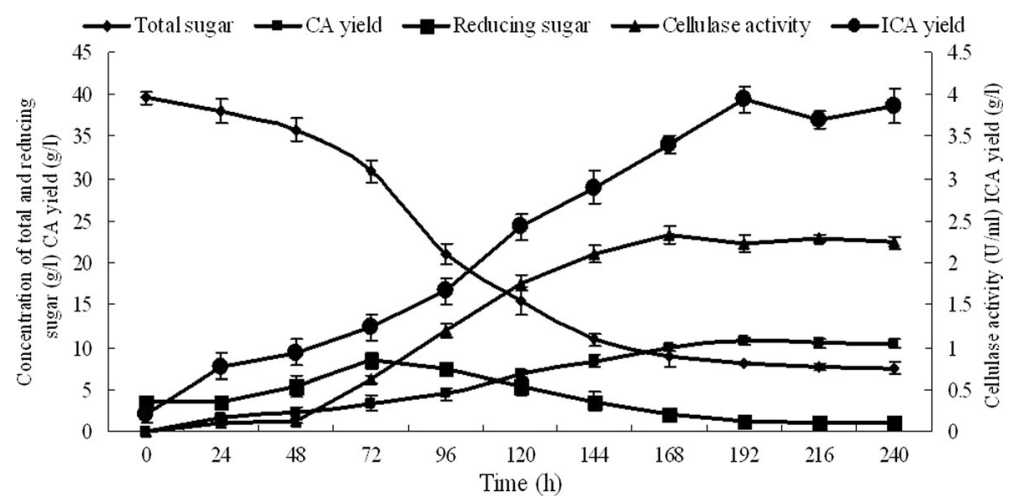

Fig. 3 Time course of total sugar change, reducing sugar change, cellulose activity, CA yield, and isocitric acid yield in the PSM. Data are given as mean $\pm \mathrm{SD}, n=3$ 
Y. lipolytica SWJ-1b was inoculated into the medium containing $40.0 \mathrm{~g} / 1$ pretreated straw, there was no growth (data not shown).

However, when the immobilized mycelia of $T$. reesei were co-cultivated with the free cells of $Y$. lipolytica SWJ-1b in the PSGM containing $40.0 \mathrm{~g} / 1$ pretreated straw, the cellulase activity produced by the immobilized $T$. reesei reached to the maximum of $1.9 \mathrm{U} / \mathrm{ml}$ at $144 \mathrm{~h}$, and the yields of CA and ICA were 32.8 and $4.7 \mathrm{~g} / 1$, respectively, at the end of the fermentation which had lasted for $288 \mathrm{~h}$ (data shown in Fig. 4). The result in Fig. 4 also shows that $86.7 \%$ of total sugar in the medium was utilized by the co-cultures. There were only free cells of $Y$. lipolytica SWJ-1b, and no mycelia growth was detected (data not shown) in the medium at the end of coculture in both PSM and PSGM.

In our previous studies, it was found that the highest amount of CA $(23.4 \mathrm{~g} / \mathrm{l})$ was accumulated in the same yeast cells when it grew in the production medium containing $40.0 \mathrm{~g} / \mathrm{l}$ hydrolysate of pretreated straw. This demonstrates that the yeast could produce more CA when it was co-cultivated with the immobilized $T$. reesei than when it grew in the production medium containing $40.0 \mathrm{~g} / \mathrm{l}$ hydrolysate of pretreated straw. This may be due to the more reducing sugar in the medium that has negative effects on CA production. In the study of Lazar et al. [25], SUC2 gene in Saccharomyces cerevisiae was cloned and transformed into the chromosome of $Y$. lipolytica, and the transformant $Y$. lipolytica A-101-B56-5 could produce $45.0 \mathrm{~g} / \mathrm{l}$ of CA $(0.6 \mathrm{~g} / \mathrm{g})$ directly from sucrose. Considering that cellulase constitutes several components [26], it will be a fussy and dubious work to express heterogenous cellulase in $Y$. lipolytica. It seems that co-cultivating T. reesei with $Y$. lipolytica $\mathrm{SWJ}-1 \mathrm{~b}$ is an effective method to produce CA directly from the pretreated straw which has greatly simplified the process of producing CA from the pretreated straw cellulose.

It was discovered that the addition of saturated fatty acid to a medium containing $150.0 \mathrm{~g} / 1$ glucose caused a drastic increase in CA production (42.9 g/l) by Y. lipolytica ACA-DC 50109 [27]. In contrast, in the diluted olive-mill wastewaters enriched with high glucose amounts (initial sugar concentration, $65.0 \mathrm{~g} / \mathrm{l}$ ), a notable quantity of total CA was produced $(28.9 \mathrm{~g} / \mathrm{l})$ by Y. lipolytica ACA-DC 50109 [28]. It was found that the maximum concentration of CA produced by $Y$. lipolytica K-168 in diluted carrot juice medium supplemented with glucose was $62.6 \mathrm{~g} / 1$ [29]. This means that the yeast Y. lipolytica SWJ-1b used in this study could produce much more $\mathrm{CA}$ than any other strains of $Y$. lipolytica, and the utilization of the pretreated straw was rather high and this is the first time to report that the pretreated straw was

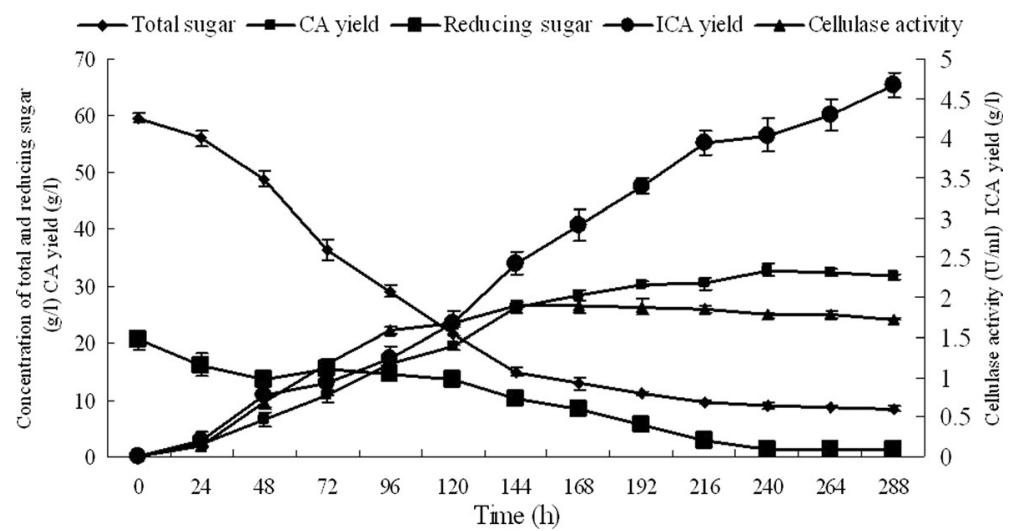

Fig. 4 Time course of total sugar change, reducing sugar change, cellulose activity, CA yield, and isocitric acid yield in the PSGM. Data are given as mean $\pm \mathrm{SD}, n=3$ 
directly converted into CA by Y. lipolytica. Furthermore, the supplementary glucose can be used by the CA producer before cellulose is being hydrolyzed, and the high initial concentration of the glucose could restrict the generation of cellulase so that more carbon resource is converted to CA rather than cellulase.

\section{Direct Conversion of the Pretreated Straw into CA During 10-1 Fermentation}

In a 10-1 fermentor, the immobilized mycelia of T. reese $i$ were co-cultivated with the free cells of Y. lipolytica SWJ-1b in 8.01 of the PSGM containing $100.0 \mathrm{~g} / 1$ pretreated straw. At the end of the fermentation, only Y. lipolytica SWJ-1b was found in the liquid culture (data not shown). Then, CA and ICA yield concentration of total and reducing sugar and the activity of cellulose were determined during the fermentation. It can be seen from the data in Fig. 5 that the cellulose activity of $T$. reesei reached the highest level $(1.9 \mathrm{U} / \mathrm{ml})$ within $168 \mathrm{~h}$ of the cultivation. Under such conditions, CA and ICA production reached to 83.4 and $8.8 \mathrm{~g} / \mathrm{l}$, respectively. The results in Fig. 5 also indicate that $80.7 \%$ of the total sugar was utilized by the co-cultures at the end of the fermentation.

So far, inulin [30] and extract of Jerusalem artichoke tubercles [31], glycerol [32], beet molasses [33], fructose [34], pure glycerol, and glycerol-containing waste [35] have been used as the substrates for CA production. It has been reported that the pretreated straw contains a large amount of glucose, and these are very easily obtained. Especially, the price of the pretreated straw is very low. Therefore, the pretreated straw is one of the most suitable substrates used in biotechnology.

From the results, we found that there was considerable total sugar and reducing sugar that remained in the medium at the end of the fermentation. Papanikolaou et al. [36] reported that when the fermentation was proceeded in the medium with high concentration of glycerol $(164.0 \mathrm{~g} / \mathrm{l})$, notable quantities of glycerol $(62.5 \mathrm{~g} / \mathrm{l})$ were remained in the fermentation broth even though the fermentation time was remarkably long $(600 \mathrm{~h})$. This indicated that in this study, the pretreated straw cellulose in the medium might had been used effectively for producing CA in the fermentation. It is known that the main component of cellulose is glucose and xylose [37], and the latter could not be used by Y. lipolytica, which maybe the other reason of the comparative low utilization of the pretreated straw. Thus, xylose reductase and xylitol dehydrogenase genes from Pichia stipitis and xylulokinase gene from $S$. cerevisiae being transformed into Y. lipolytica might realize the co-fermentation of glucose and xylose [37], and

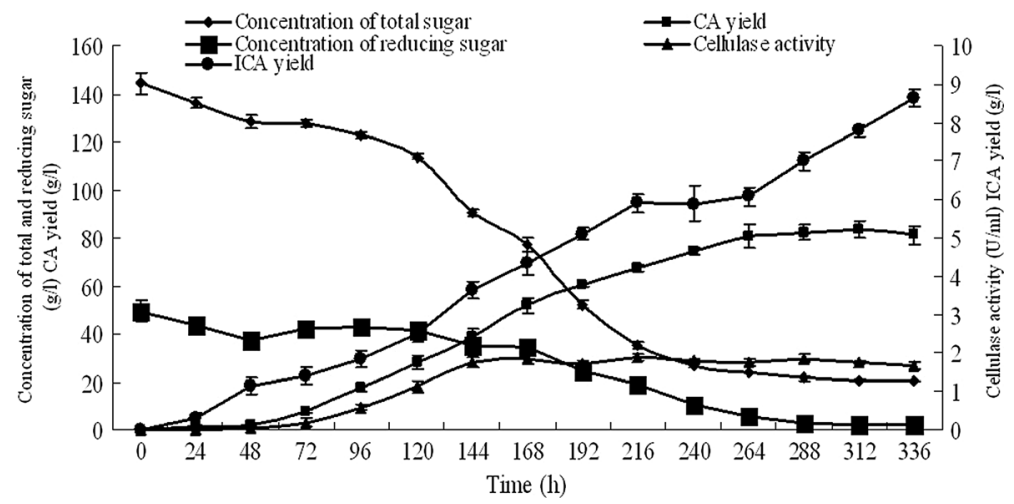

Fig. 5 Time course of total sugar change, reducing sugar change, cellulose activity, CA yield, and isocitric acid yield in the 10-1 fermentation in PSGM. Data are given as mean $\pm \mathrm{SD}, n=3$ 
the CA production of $Y$. lipolytica may be further improved using the pretreated straw. This work is being done in the laboratory.

\section{Conclusions}

In this study, the free cells of $Y$. lipolytica SWJ-1b were co-cultured with the immobilized mycelia of $T$. reesei which produced a high level of cellulase; Y. lipolytica SWJ-1b could produce $10.7 \mathrm{~g} / \mathrm{l} \mathrm{CA}$ from $40.0 \mathrm{~g} / 1$ pretreated straw and $32.8 \mathrm{~g} / \mathrm{l} \mathrm{CA}$ from $40.0 \mathrm{~g} / 1$ pretreated straw supplemented with $20.0 \mathrm{~g} / \mathrm{l}$ glucose. When the co-cultures were grown in $10-1$ fermentor, Y. lipolytica SWJ-1b could produce $83.4 \mathrm{~g} / \mathrm{l} \mathrm{CA}$ from $100.0 \mathrm{~g} / 1$ pretreated straw supplemented with $50.0 \mathrm{~g} / \mathrm{l}$ glucose.

Acknowledgments This work was supported by Jiangsu Key Laboratory for Biomass-based Energy and Enzyme Technology (Huaiyin Normal University). This research was supported by Grant 31200023 from the National Natural Science Foundation of China.

\section{References}

1. Javed, S., Asgher, M., \& Sheikh, M. A. (2010). Strain improvement through UV and chemical mutagenesis for enhanced citric acid production in molasses-based solid state fermentation. Food Biotechnology, 24(2), 165-179.

2. Soccol, C. R., Vandenberghe, L. P. S., Rodrigues, C., \& Pandey, A. (2006). New perspectives for citric acid production and application. Food Technology and Biotechnology, 44(2), 141-149.

3. Finogenova, T. V., Puntus, I. F., Kamzolova, S. V., Lunina, Y. N., Monastyrskaya, S. E., Morgunov, I. G., et al. (2008). Mutant Yarrowia lipolytica strains producing citric acid from glucose. Applied Biochemistry and Microbiology, 44(2), 197-202.

4. Stottmeister, U., \& Hoppe, K. (1991). Organische Genußs"auren. In: Ruttloff, H. (Ed.), Lebensmittelbiotechnologie, Entwicklungen und Aspekte. Akademie-Verlag Berlin 516-547.

5. Wang, F., Yue, L. X., Wang, L., Madzak, C., Li, J., Wang, X. H., et al. (2009). Genetic modification of the marine-derived yeast Yarrowia lipolytica with high-protein content using a GPI-anchor-fusion expression system. Biotechnology Progress, 25(5), 1297-1303.

6. Liu, X. Y., Chi, Z., Liu, G. L., Wang, F., Madzak, C., \& Chi, Z. M. (2010). Inulin hydrolysis and citric acid production from inulin using the surface-engineered Yarrowia lipolytica displaying inulinase. Metabolic Engineering, 12, 469-476.

7. Chi, Z. M., Zhang, T., Cao, T. S., Liu, X. Y., Cui, W., \& Zhao, C. H. (2011). Biotechnological potential of inulin for bioprocesses. Bioresource Technology, 102, 4295-4303.

8. Sun, Y., \& Cheng, J. (2002). Hydrolysis of lignocellulosic materials for ethanol production: a review. Bioresource Technology, 83(1), 1-11.

9. Sternberg, D. (1976). Production of cellulase by Trichoderma. Biotechnology and Bioengineering Symposium, 6, 35-53.

10. Ross, A., Schfigerl, K., \& Scheiding, W. (1983). Cellulase production by Trichoderma reesei. European Journal of Applied Microbiology and Biotechnology, 18, 29-37.

11. Turker, M., \& Mavituna, F. (1987). Production of cellulose by freely suspended and immobilised cells of Trichoderma reesei. Enzyme and Microbial Technology, 9(12), 739-743.

12. Moayednia, N., Ehsani, M. R., Emamdjomeh, Z., Asadi, M. M., Mizani, M., \& Mazaheri, A. F. (2009). The effect of sodium alginate concentrations on viability of immobilized lactobacillus acidophilus in fruit alginate coating during refrigerator storage. Journal Australian Journal of Basic and Applied Sciences, 3(4), 3213-3216.

13. Tangnu, S. K., Blanch, H. W., \& Charles, R. (1981). Enhanced Production of Cellulase, Hemicellulase, and P-Glucosidase by Trichoderma reesei (Rut C-30). Biotechnology and Bioengineering, 23, 1837-1849.

14. Spiro, R. G. (1966). Analysis of sugars found in glycoproteins. Methods in Enzymology, 8, 3-26.

15. Chi, Z. M., Liu, J., \& Zhang, W. (2001). Trehalose accumulation from soluble starch by Saccharomycopsis fibuligera sdu. Enzyme and Microbial Technology, 28(2-3), 240-246. 
16. Camp, B. J., \& Farmer, L. (1967). A rapid spectrophoyometer method for the determination of citric acid in blood. Clinical Chemistry, 13, 501-505.

17. Jobanputra, A. H., Karode, B. A., \& Chincholkar, S. B. (2011). Calcium alginate as supporting material for the immobilization of rifamycin oxidase from Chryseobacterium species. Biotechnology, Bioinformatics and Bioengineering, 1(4), 529-535.

18. Calinescu, I., Chipurici, P., Trifan, D., \& Badoiu, C. (2012). Immobilisation of Saccharomyces cerevisiase for the production of bioethanol. UPB Scientific Bulletin, Series B, 74(1), 1454-2331.

19. Moosavi-Nasab, M., \& Majdi-Nasab, M. (2007). Cellulase Production by Trichoderma reesei using Sugar Beet Pulp. Iran Agricultural Research, 25(2), 26(1-2), 107-116.

20. Szengyel, Z., \& Zacchi, G. (2000). Effect of acetic acid and furfural on cellulase production of Trichoderma reesei RUT C30. Applied Biochemistry and Biotechnology, 89, 31-42.

21. Mandels, M., \& Weber, J. (1969). The production of cellulases. In: Cellulases and Their Applications. Advances in Chemistry Series 93, 391-414.

22. Zhao, C. H., Chi, Z., Zhang, F., Guo, F. J., Mei, L., Song, W. B., et al. (2011). Direct conversion of inulin and extract of tubers of Jerusalem artichoke into single cell oil by co-cultures of Rhodotorula mucilaginosa TJY15a and immobilized inulinase-producing yeast cells. Bioresource Technology, 102, 6128-6133.

23. Hui, Y. S., Amirul, A. A., Yahya, A. R. M., \& Azizan, M. N. M. (2010). Cellulase production by free and immobilized Aspergillus terreus. World Journal of Microbiology and Biotechnology, 26(1), 79-84.

24. Parascandola, P., Branduardi, P., \& de Alteriis, E. (2006). PVA-gel (Lentikats ${ }^{\circledR}$ ) as an effective matrix for yeast strain immobilization aimed at heterologous protein production. Enzyme and Microbial Technology, 38, 184-189.

25. Lazar, Z., Walczak, E., \& Robak, M. (2011). Simultaneous production of citric acid and invertase by Yarrowia lipolytica SUC+ transformants. Bioresource Technology, 102(13), 6982-6989.

26. Duff, S. J. B., \& Murray, W. D. (1996). Bioconversion of forest products industry waste cellulosics to fuel ethanol: a review. Bioresource Technology, 55(1), 1-33.

27. Papanikolaou, S., Galiotou-Panayotou, M., Chevalot, I., Komaitis, M., Marc, I., \& Aggelis, G. (2006). Influence of glucose and saturated free fatty acid mixtures on citric acid and lipid production by Yarrowia lipolytica. Current Microbiology, 52(2), 34-142.

28. Papanikolaou, S., Galiotou-Panayotou, M., Fakas, S., Komaitis, M., \& Aggelis, G. (2008). Biotechnological valorisation of raw glycerol discharged after bio-diesel (fatty acid methyl esters) manufacturing process: Production of 1, 3-propanediol, citric acid and single cell oil. Bioresource Technology, 99(7), 2419-2428.

29. Yalcin, S. K. (2012). Enhancing citric acid production of Yarrowia lipolytica by mutagenesis and using natural media containing carrot juice and celery byproducts. Food Science and Biotechnology, 21(3), 867874.

30. Liu, X. Y., Chi, Z., Liu, G. L., Madzak, C., \& Chi, Z. M. (2013). Both decrease in ACL1 gene expression and increase in ICL1 gene expression in marine-derived yeast Yarrowia lipolytica expressing INU1 gene enhance citric acid production from Inulin. Marine Biotechnology, 15(1), 26-36.

31. Wang, L. F., Wang, Z. P., Liu, X. Y., \& Chi, Z. M. (2013). Citric acid production from extract of Jerusalem artichoke tubers by the genetically engineered yeast Yarrowia lipolyticastrain 30 and purification of citric acid. Bioprocess and Biosystems Engineering, 36, 1759-1766.

32. Papanikolaou, S., Muniglia, L., Chevalot, I., Aggelis, G., \& Marc, I. (2002). Yarrowia lipolytica as a potential producer of citric acid from raw glycerol. Journal of Applied Microbiology, 92(4), 737-744.

33. Wang, J., Wen, X., \& Zhou, D. (2000). Production of citric acid from molasses integrated with in-situ product separation by ion-exchange resin adsorption. Bioresource Technology, 75(3), 231-234.

34. Yalcin, S. K., Bozdemir, M. T., \& Ozbas, Z. Y. (2009). A comparative study of citric acid production kinetics of two Yarrowia lipolytica strains in two different media. Indian Journal of Biotechnology, 8(4), 408-417.

35. Kamzolova, S. V., Fatykhova, A. R., Dedyukhina, E. G., Anastassiadis, S. G., Golovchenkoand, N. P., \& Morgunov, I. G. (2011). Citric acid production by yeast grown on glycerol-containing waste from biodiesel industry. Food Technology \& Biotechnology, 49(1), 65-74.

36. Galiotou-Panayotou, M., Komaitis, M., Marc, I., Aggelis, G., (2008). Biotechnological valorisation of raw glycerol discharged after bio-diesel (fatty acid methyl esters) manufacturing process: production of 1, 3propanediol, citric acid and single cell oil. Biomass and Bioenergy, 32(1), 60-71.

37. Ho, N. W. Y., Chen, Z., \& Brainard, A. P. (1998). Genetically engineered Saccharomyces yeast capable of effective cofermentation of glucose and xylose. Applied and Environmental Microbiology, 64(5), 1852-1859. 